\title{
Forecasting potential yields under uncertainty using fuzzy cognitive maps
}

\author{
Mohammed A. Al-Gunaid ${ }^{1 *} \mathbb{D}$, Irina I. Salygina' ${ }^{1}$ Maxim V. Shcherbakov', Vladislav N. Trubitsin ${ }^{1}$ and \\ Peter P. Groumpos ${ }^{2}$
}

\begin{abstract}
Background: The aim of the study is identification of factors influencing the reduction of the potential maximum yield of winter wheat in weather conditions of dry farming in European part of Russia, Volgograd region. The novelty of the work is forecasting potential yields under uncertainty that allows to assess the risks and potential threats that can influence and maximize the potential yield. To solve this problem, the tool for formalization, analysis and modeling of semi-structured systems and processes Fuzzy Cognitive Maps (FCM) is used.

Results: Based on disparate and heterogeneous information about the multitude of external influences on crop formation during plant photosynthesis, a model for analyzing the level of influencing factors on the target factor is constructed and an effective control impact scenario is developed. This model is used to identify the factors, where each one of them iteratively passes from the initial value to the stable one according to the chosen formula, based on which, the influence of the factors on each other are determined.

Conclusions: The conclusions obtained as a result of the work confirm the concept of precision farming: the quantity and quality of innovation in agriculture depends on the ability to apply it effectively in the field. Developed method of predicting potential yield levels can be used not only to model future agricultural performance, but also to estimate harvested yields.
\end{abstract}

Keywords: Forecasting, Agriculture, Fuzzy cognitive maps

\section{Introduction}

Agricultural activity is one of the most important parts of the world economy. Agriculture inevitably affects the land and, in many cases, shapes the landscape itself. Supporting economic processes, the agro-industrial complex provides the population with food reserves. In addition, it is a rather conservative sphere of human activity. At the same time, in agriculture a lot of innovations are being introduced, which contribute to reducing production risks and improving the quality of final products taking into account the global environmental situation.

\footnotetext{
*Correspondence: mohammadalgunaid@gmail.com

${ }^{1}$ Volgograd State Technical University, Volgograd, Russia

Full list of author information is available at the end of the article
}

For decades, agriculture has been associated with the production of essential food crops. At present, agriculture beyond farming includes forestry, dairy, fruit cultivation, poultry, beekeeping, mushroom, arbitrary, etc. Today, processing, marketing, and distribution of crops and livestock products, etc. are all acknowledged as part of current agriculture. Thus, agriculture could be referred to as the production, processing, promotion, and distribution of agricultural products. Agriculture plays a critical role in the entire life of a given economy of a country. Agriculture is the backbone of the economic system of a given country. In addition to providing food and raw material, agriculture also provides employment opportunities to a very large percentage of the population.

Forecasting methods are used to draw up expectations about future results on the basis of already available and original author(s) and the source, provide a link to the Creative Commons licence, and indicate if changes were made. The images or other third party material in this article are included in the article's Creative Commons licence, unless indicated otherwise in a credit line to the material. If material is not included in the article's Creative Commons licence and your intended use is not permitted by statutory regulation or exceeds the permitted use, you will need to obtain permission directly from the copyright holder. To view a copy of this licence, visit http://creativecommons.org/licenses/by/4.0/. The Creative Commons Public Domain Dedication waiver (http://creativeco mmons.org/publicdomain/zero/1.0/) applies to the data made available in this article, unless otherwise stated in a credit line to the data. 
processed data. In this paper, forecasting is considered as a calculation of theoretically possible yield growth provided by climatic, soil and material-technical resources. It can gives the chance to assume the final result of the process of yield formation during photosynthesis of plants in certain soil-climatic conditions [1]. The purpose of the model is to identify the factors influencing the reduction of the potential maximum yield and to identify effective scenarios of impact on the modelled process.

Fuzzy Cognitive Map (FCM) [2] highlight the factors and the relationships between them. Such a framework reflects an idealized structure of knowledge on the subject area. The main source of information is expert assessment of the state of concepts and mutual causeeffect effects. The principle of point impact on the factors influencing the formation of yield is used in the field of knowledge such as yield programming. By means of stage-by-stage influence on the list of factors, an agronomist optimizes the development of plants during the growing season and thus there is an impact on the development of yield. Decisive factors are fertilizers, cultivation technology, irrigation, variety, plant protection from diseases, pests, weeds, etc. [1]. In this way, we have a list of concepts that can be offered to assessors.

Fuzzy cognitive maps are currently a popular tool for modeling causal relationships between concepts in complex systems.

Thus, in the study [3], FCM is used to identify the relationship of critical factors affecting the transition of energy to bioeconomy options. Areas of this research include scenarios highlighting the impact of energy supply on urbanization and an increase in the number of urban actors influencing low-carbon policy decisions. The tool proposed by the authors helps guide competent authorities and decision makers towards the transition from sustainable energy to decarbonization.

Paper [4] describes an approach to assessing resilience and its impact on investment decisions in the water supply and sanitation sector, which reflects different perspectives of sustainability by identifying and comparing cognitive maps various agents both inside and outside the wastewater treatment plant. FCM is used as a practical tool to identify subjective views on resilience mechanisms and demonstrate co-production methodology with wastewater professionals in the Belfast area of Northern Ireland. The authors believe that the proposed approach can be useful for the purposes of strategic planning within the enterprise and for improving interagency interaction between both internal and external agents.

The authors of [5] use fuzzy cognitive maps (FCM) to optimize municipal waste management systems (MWMS). By applying FCM to Land of Fire, the understanding of the internal dynamics of the MWMS was improved to formulate optimal policy strategies and support decision makers in their efforts to identify problems, gaps and potential solutions.

As an object of modeling, the paper considers the features of dry agriculture in Russia, Volgograd region on the basis of data from an experimental farm located in the Mikhailovsky district. The purpose of this study is to determine the theoretically possible maximum yield of winter wheat, which can be obtained in the current meteorological conditions.

To solve this problem, we use the tools of formalization, analysis and modeling of weakly structured systems and processes, as forecasting (in this paper-fuzzy cognitive maps) in general works not only to assess the immediate future, but also gives an approximate economic assessment, evaluation of preliminary work, identification of risks for early impact and minimization of potential losses in the crop. Under different conditions, it would be enough to study the statistical data of yield and build the level of expectations for the period of interest depending on changes in the level of agricultural machinery, mechanization, labor organization and use planning tools.

The purpose of the developed method of forecasting is to identify risks and threats at early stages, to determine the effective impacts, moderation of existing methods of agricultural management and increase the efficiency of agricultural marketing.

\section{Related works}

It is traditionally required for the specific support of agrarian branch development to use various conceptual, mathematical and geoinformation models $[6,7]$. At the same time, there are a number of limitations to modeling the functioning and development of agrogeosystems. This is due to the fact that any model is a less complex reproduction of the studied object, so it reproduces only a small part of the features of the functioning and development of agrogeosystems in general [8]. An important limitation of modeling is the correct choice of mathematical methods for modeling, which, first, should be as simple as possible, and second, it allowed more adequate interpretation and explanation of the results of modeling. In addition, the feature of agro-geographical studies is in the large volume of used initial information, its heterogeneity and uncertainty. All this causes the need to develop qualitatively new models of decision-making in the agricultural sector to identify and study the territorial laws and features of modern innovative development of agriculture. For these purposes, it is appropriate to use the associated system of traditional methods (optimization models), methods of data intellectual analysis (Data Mining), expert evaluation, simulation of mathematical and geoinformational models [8]. 
At the moment, several classifications for the development of forecasting models in crop production can be identified. Depending on the objectives of the study, the authors' views on the problems of crop forecasting change. Harmful factors can be studied, following the development of the mathematical models, which it will manage the yield, predict the potential yield, where the researcher can determine the approximate level of the final product, predict the actual possible yield and where specific figures in measurable units are given. Conclusions and results of the models are checked on the results of the actual yield in production or are given to the expert committee for evaluation.

If we consider in more detail, the forecasts are divided by the directions of study: life expectancy of plants, the factors used in the model and their number (single and multifactor), the methods of forecasting the state of the agricultural system under consideration. Consideration of the territory of the experiments is incorrect, because there is no universal and uniform coverage of all variations of soil and climatic conditions.

In terms of the life expectancy of cultivated crops, there is a division into annual [9-12] and perennial. [13-16]. Different features of crop cultivation are considered, which depend both on the peculiarities of plant systematics (cereals, legumes, etc.) and on the areas of study (India, Brazil, South America, etc.). Researchers either study the peculiarities of a particular plant or make interspecific comparisons. Such direction of researches is actual as an auxiliary technique on calculation of profitability of agricultural works.

Factors of forecasting models are based on different parts of plants: influence on the root system through the spread of organic matter [14, 17-19], plant appearance [10], pest and disease detection [20, 21], Leaf cover participation in carbon movement $[22,23]$. In these works, researchers more often consider the unilateral problem of the influence of a group of factors from one area on the final yield level. Different ways of human intervention in natural processes to improve growing technology and fieldwork efficiency are considered. Data from satellite images are seldom used (vegetation indexes, image recognition).

Among the methods used for yield forecasting linear, multiple linear and stepwise linear regression are used $[11,12,22]$, machine learning methods $[10,24-26]$ and Fuzzy Cognitive Maps [6, 14], interpolation [17], random and cubic forests $[7,19,22]$. In many sources, the authors compare several methods and regression analysis is most often taken as the optimal solution [27]. However, these conclusions can be in disagreement on the basis of experimental fields in the Volgograd region. In Fig. 1 ( $X$-axis indicates the number of fields sown in wheat in each

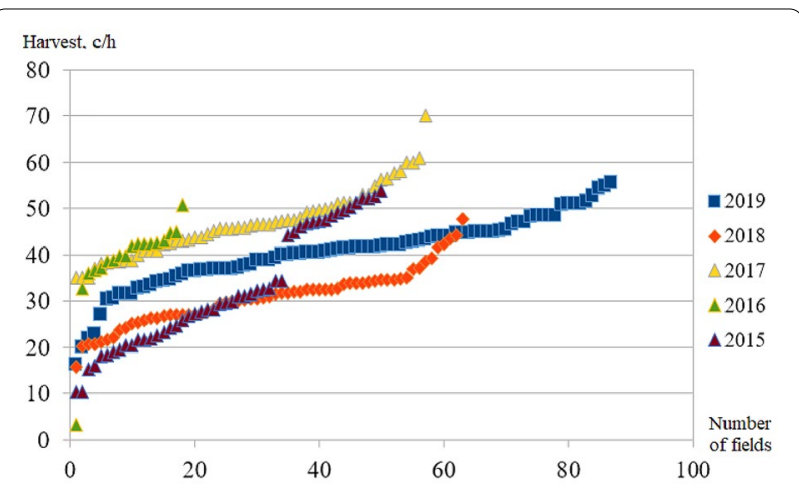

Fig. 1 Yield distribution of winter wheat on test fields

particular year, $Y$-axis indicates the number of harvested crops in centners per hectare), the statistics of yield distribution on experimental fields for the last 5 years, where the dependence in the appearance of fields with a deviation from the general linear trend at the beginning and end is traced for of each of the graphs. Therefore, we suggest that the laws of yield distribution do not always assumes linear dependence. This reasoning should be taken into consideration in a separate study.

The aim of this paper is to process a large amount of heterogeneous and unstructured information to determine the reasons for the decrease in the potential maximum yield level. Therefore, a Fuzzy Cognitive Map (FCM) toolkit is used. To unify the disparate information, the expert assessment of the state for each of the selected factors are used. Due to this, we are able to take into account the peculiarities of both the technology of land cultivation and soil-climatic data. The conclusions are more specific and related to the opinion and experience of the experts, but can serve as a basis for future research. The main goal of the method is to identify the influence of each factor on the target value and iterative calculations before the search for a stable state of the model. Machine learning methods can be used to improve Fuzzy Cognitive Mapping (FCM) settings [28].

Consider a study on fruit crop yield prediction based on the content of chemical elements in the soil [14]. In this example, there are nine concepts, of which one is output (yield), three describe soil properties (electrical conductivity, clay and sand content) and the remaining ones are responsible for the content of chemical elements in the soil (zinc, phosphorus, etc.). In the influence matrix, the factors do not influence each other, but only the target yield factor. We believe that for the effective use of Fuzzy Cognitive Map (FCM) tools it is necessary to use various factors of influence. This trend is noticable in the analysis of the following works [13, 14, 29]. For example, the work is not only related to the topic of agriculture, as the study 
of known electronic information bases (Scopus, etc.). Research in the field of economics is more popular in the Russian segment of science. The Fuzzy Cognitive Map (FCM) method has been used extensively in the field of decision-making. A significant number of research works have been conducted related to the use of Fuzzy Cognitive Maps (FCM) to identify the level of mutual influence of factors and determine the scenarios of behavior of the system $[30,31]$.

As can be seen from the review of related works, predicting potential yields by identifying risks and threats in the early stages of growing crops is an urgent task, and FCM are a modern and suitable approach for this.

\section{Methodology}

This section contains a description of the basic concepts and principles of FCM functioning.

Fuzzy Cognitive Maps (FCMs) is a new methodology for modeling complex dynamic systems (CDS) and has been around only for the last 30-35 years. FCMs exploit the knowledge and experience of people. fuzzy cognitive maps came as a combination of the methods of fuzzy logic and neural networks. They constitute a computational method that is able to examine situations during which the human thinking process involves fuzzy and/or uncertain descriptions [32, 33]. They are directed graphs capable of modeling interrelationships or causalities existing among concepts, such as example, given at Fig. 2. They are the evolution of the Cognitive Maps, which were introduced by Axelrod. It's a soft computing methodology that gives users the ability to encounter problems in the same way the human mind does; using a conceptual procedure, which can include ambiguous or fuzzy descriptions. Therefore, FCMs offer a simple, fast, flexible, economical, and

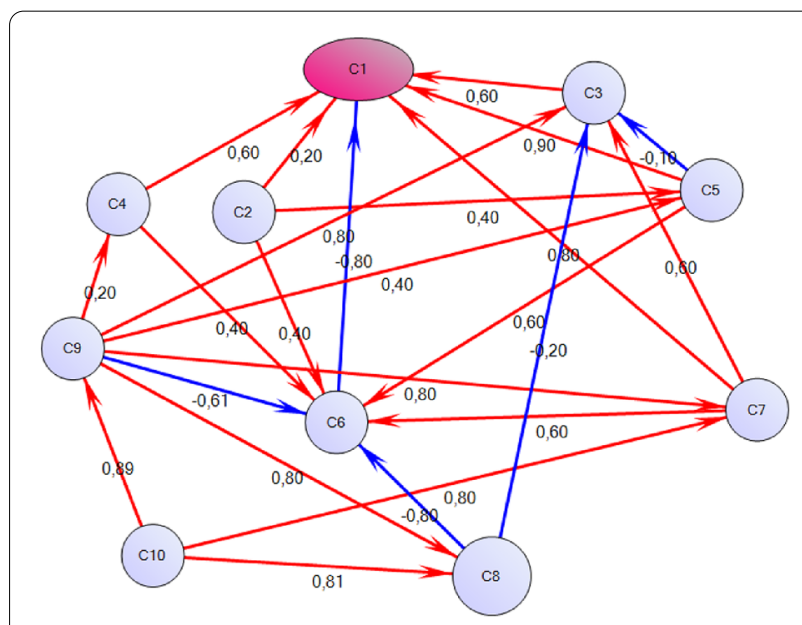

Fig. 2 Graphic representation of the fuzzy cognitive map versatile approach to a variety of problems which are extremely complex and a purely mathematical approach would be time consuming, laborious and require wasting many resources without finding meaningful and realistic solutions at the end.

An FCM consists of: concepts: are all characteristics of a complex system; events, states, inputs, outputs, events, trends, constraints, controls, type of decisions. Nodes: represent the system's concepts. Arrows: interconnection between nodes. Show the cause-effect relationship between them. Between concepts, there are three possible types of causal relationships that express the type of influence from one concept to another:

- $W_{i j}>0$, positive causality. 'When the value of node $C_{i}$ increases, the value of node $C_{j}$ increases, and, respectively, when the value of node $C_{i}$ decreases, the value of node $C_{j}$ also decreases.

- $W_{i j}<0$, negative causality. When the value of node $C_{i}$ increases, the value of node $C_{j}$ decreases, and when the value of node $C_{i}$ decreases, the value of node $C_{j}$ increases.

- $W_{i j}=0$, zero causality. There is no causal relationship between node $C_{i}$ and node $C_{j}$.

- Zero causality also means there is no correlation between node $C_{i}$ and node $C_{j}$.

Remark: We must stress that Causality always implies Correlation, but the reverse does not hold. The numerical value of the weight of each $W_{i j}$ interface between the nodes $C_{i}$ and $C_{j}$ indicates the degree to which the value of the variable of a node has a causality with the variable of the interconnected node being taken into account. The numeric value of each $W_{i j}$ interface weight belongs to the interval $[-1.1]$.

$$
A_{i}^{(k+1)}=f\left(k_{2} A_{i}(k)+k_{1} \sum_{j=1, j \neq i}^{N} A_{j}(k) W_{j i}\right),
$$

where:

- $A_{i}(k+1)$ : the value of the node $C_{i}$ at time $k+1$

- $A_{j}(k)$ : the value of node $C_{j}$ at time $k$

- $W_{i}$ : the weight of the interconnection of node $C_{j}$ to node $C_{i}$

- $k_{1}$ : constant expressing the effect of interconnected nodes on the configuration of the new node $A_{i}$ value

- $k_{2}$ : constant representing the contribution of the previous node value to the calculation of the new node 
and $f$ is the sigmoid function 2 :

$$
f=\frac{1}{1+e^{\lambda x}},
$$

where $\lambda>0$ determines the steepness of function $f$. The FCM's concepts are given some initial values which are then changed depending on the weights and the way the concepts affect each other. The calculations stop when a steady state is achieved the concepts' values become stable. In most applications, $k_{1}$ and $k_{2}$ are set equal to 1 . The FCM approach is based on expert's knowledge for the construction of matrix $W_{i j}$. This experience is not always reliable though. That is the reason why the weights $W_{i j}$, need to be trained by learning algorithm. Several learning principles originally developed for ANNs have been applied to FCM modelling. These approaches were based on the concept of Hebbian learning.

More specifically Nonlinear Hebbian learning method has been used to many applications. In this learning algorithm the nodes are triggered simultaneously and interact in the same iteration step with their values to be updated through this process of interaction. The training weight algorithm is computed as follows:

$$
\begin{aligned}
W_{i j}(k)= & g * W_{i j}(k-1)+h * A_{j}(k-1) * \\
& *\left(A_{i}(k-1)-\operatorname{sgn}\left(W_{i j}\right) * W_{i j}(k-1) * A_{j}(k-1)\right),
\end{aligned}
$$

where the coefficient $h$ is a very small positive scalar factor called learning parameter, and the coefficient g called weight reduction parameter. Two stopping criteria terminate the procedure. The first one concerns the minimization of the sum of the square differences between each desired output concept $i\left(\mathrm{DOC}_{\mathrm{i}}\right)$ and a target value $T_{i}$ :

$$
F_{1}=\sqrt{\sum_{i=1}^{m}\left(\mathrm{DOC}_{\mathrm{i}}-\mathrm{T}_{\mathrm{i}}\right)^{2}} .
$$

$T_{i}$ is defined as the mean value of the range of $\mathrm{DOC}_{i}=\left[T_{i}^{\min }, T_{i}^{\max }\right]$ and $m$ is the number of the desired output nodes. The second criterion is the minimization of the variation of two subsequent values of desired output concepts [33]:

$$
F_{2}=\left|\mathrm{DOC}_{\mathrm{i}}^{\mathrm{k}+1}-\mathrm{DOC}_{\mathrm{i}}^{\mathrm{k}}\right| .
$$

There are modifications to the Eq. (1), where the level of confidence in the solution is calculated in addition [34] or where a proportion of the contribution of the previous value of the concept is added to the equation in the calculation of the new value and the influence of the related concepts on the configuration of the new state is separately taken into account $A_{i}[6]$.
The analysis of the fuzzy cognitive map begins with the determination of the total influence of the factors on each other, taking into account both direct and indirect influence, when one factor affects the other through a chain of intermediate factors. For this purpose, the fuzzy cognitive map is first presented in the form of a matrix of contiguity, in which the weights of the direct connections between the factors are set out. Then a matrix of transitive closure is constructed for it. As a result, we obtain maximal positive and negative connections between the concepts by module. Then the final mutual influence of factors on each other is calculated:

$$
p_{i j}=\operatorname{sign}\left(\mathrm{a}_{\mathrm{ij}}+\mathrm{b}_{\mathrm{ij}}\right) * \max \left(\left|\mathrm{a}_{\mathrm{ij}}\right|,\left|\mathrm{b}_{\mathrm{ij}}\right|\right),
$$

where sign: signum function, $a_{i j}$ : total positive impact, $b_{i j}$ : the total negative impact. The signal function shows which sign the actual number has. If the number is negative, the function has a value of -1 . If the number is positive, the function is equal to one. If the number is zero, the value of the function will also be zero [35].

The starting point of modeling is the vector of initial values of input factors. At the preparatory stage the target and control factors are singled out. Concepts, on which the subject of control has an opportunity to influence, are chosen as control factors. Concepts that characterize the state of the control object and the purpose of model construction are chosen as target factors.

Then, there is a structurization of information for the selection of basic concepts, that characterize a particular indicator of influence or group of such, which is reasonable to use as a single factor (for example, the concept "Hostile factors" changed after several experiments and combines the negative impact of factors on the yield "Weeds", "Pests", "Disease", because in this study it is not important to us, where we are getting the negative impact from, and it is advisable to combine them together). For each of the concepts, development trends are defined. For links, values are set according to the scale of linguistic scores, the numerical equivalent of which is stored in the range from minus to plus units (see Table 1).

Assessments are made after interviews or interviews with experts and decision makers. Where information is

Table 1 Linguistic scale

\begin{tabular}{ll}
\hline Linguistic evaluation & Numerical assessment \\
\hline Very weakly increases (decreases) & $0.1 ; 0.2(-0.1 ;-0.2)$ \\
Weakly enhances (weakens) & $0.3 ; 0.4(-0.3 ;-0.4)$ \\
Moderately enhances (weakens) & $0.5 ; 0.6(-0.5 ;-0.6)$ \\
Strengthens (weakens) strongly & $0.7 ; 0.8(-0.7 ;-0.8)$ \\
Very strong (weakens) & $0.9 ; 1(-0.9 ;-1)$ \\
\hline
\end{tabular}


insufficient, it is supported by analysis of available information in the form of texts or information bases.

Once the list of concepts has been defined and the relationship between them has been defined, we move on to build a Fuzzy Cognitive Map in the form of a oriented graph, where the input concepts are the basic factors from which we model the output variables.

To have an effective impact on the simulated situation, it is necessary to analyze the cause-effect relations between the factors. For this purpose, it is possible to carry out a structural analysis of fuzzy cognitive map factors to determine the consistency of control purposes with the purposes of forecasting, the effectiveness of the influence of control factors on the target ones. In this process, the consistency of the goals vector is revealed, as the control influence is made to achieve the desired changes. Managed situations are created so that the impact brings the desired result of the target factors. Therefore, it is advisable to assess the consistency of target and control factors, so that after the impact does not get an unexpected version of the development of events.

Modeling can be performed in the mode of independent and controlled development. independent development assumes preservation of existing tendencies and extrapolates the influence of other input factors. Managed development implies a point impact on the current values of the factors, which will be transferred along the chain to other concepts.

After the conclusions on the created model of the fuzzy cognitive map are formulated, the structure of the model can be corrected, the purpose of construction or criteria of estimation of results of modeling can be updated. Key Performance Indicators (KPIs) can be calculated, where qualitative indicators of reporting documentation performance for a specific agricultural division of the test company will be checked. Reporting is related to the assessment of past fieldwork and the identification of factors that affect the potential yield.

\section{Experiments}

This section contains a description of the initial situation, a set of concepts (target and control factors), edges (control vectors) and their levels of influence, formed by the authors and experts, depending on the scenarios that determine the effective control factors. For clarity, a graphical representation of the resulting FCM is formed.

According to the process of developing fuzzy cognitive maps, the number and type of concepts were defined by the expert group. The experts were representatives of the Test Farm Agronomical Service and a representative of the management staff. Individual experts were consulted on the cognitive maps. The answers of the experts during the interviewing were combined, translated according to the scale of linguistic assessments and formed into the initial vector of the concept state. The experts' assessments were translated into the following rules "if-then", that made up the interaction matrix. The same experts were presented with the results of the modeling to check compliance with expectations.

Description of the starting situation: there is an enterprise on the territory of Volgograd region with fields on the territory of about 20,000 ha. We consider the potential level of winter wheat yield as of 2019 sowing year. The specifics of agricultural activity lies in the technology of dry farming with zero tillage (No-Till), where it is important to qualify the operator and operator of the agricultural technological apparatus, timely introduction of drugs into the soil. Another distinctive feature of this technology is the mulch covering of the ground surface, which is designed to preserve the soil from erosion and contribute to the accumulation of moisture [36]. Preservation of autumn and spring moisture reserves is important for the cultivation of winter wheat. Especially when folding the conditions of dry summer. The combination of several weather factors has a strong impact on the final harvest, not only affecting the plants, but also contributing to the development of hostile factors. Previous crops are mainly winter and spring wheat (about $50 \%$ of experimental fields), chickpea (about 35\%), sunflower, flax and steam. At the time of writing, not all fields have been selected, but most of them have phosphorus content of about $11-16 \mathrm{mg} / \mathrm{kg}$, nitrogen up to $100 \mathrm{mg} / \mathrm{kg}$ and humus level of about 3-5\%. Qualification of the agronomic service influences the timely and effective application of plant protection products (IPP) and fertilizers.

The target factors are "The potential yield level", which should strive for the highest possible value, and the concept of "Hostile factors", the value of which should be as low as possible. This choice characterizes our expectations for the dynamics and direction of development of the modeling process. These goals are equally important for us, as the potential threat from pests and diseases can damage crops in production. The selected management factors are: "Fertilizers", "Plant protection products (PPP)", "Land cultivation technology", "Qualification of the agronomic service" (code each of the factors into a separate scenario of impact on the system), because by making a financial infusion into each of the concepts, we can provide a precise impact on the factor and consider how this intervention will affect the system. Thus, the basic direction for all concepts except "Hostile factors" should tend to grow positively. The values of all factors are given in the Table 2. To present the information in a compact way, the table shows four scenarios by which we will identify the effective management 
Table 2 Base factors and control vectors

\begin{tabular}{|c|c|c|c|c|c|c|c|}
\hline \multirow[t]{2}{*}{ No. } & \multirow[t]{2}{*}{ Model factors } & \multirow[t]{2}{*}{ Initial trend } & \multirow[t]{2}{*}{ Target value } & \multicolumn{4}{|c|}{ Control vectors } \\
\hline & & & & Scz 1 & Scz 2 & Scz 3 & Scz 4 \\
\hline $\mathrm{C} 1$ & Potential yield level & 0 & 1 & - & - & - & - \\
\hline $\mathrm{C} 2$ & Previous culture & 0.2 & - & - & - & - & - \\
\hline $\mathrm{C} 3$ & Soil condition & 0.4 & - & - & - & - & - \\
\hline $\mathrm{C} 4$ & Sum of accumulated temperatures & 0.4 & - & - & - & - & - \\
\hline $\mathrm{C} 5$ & Moisture stockpile & 0.9 & - & - & - & - & - \\
\hline C6 & Hostile factors & 0.6 & 0.25 & - & - & - & - \\
\hline$C 7$ & Fertilizers & 0.5 & - & - & 0.25 & - & - \\
\hline $\mathrm{C} 8$ & PPP & 0.6 & - & - & - & 0.25 & - \\
\hline C9 & Land cultivation technology & 0.2 & - & - & - & - & 0.25 \\
\hline $\mathrm{C} 10$ & Qualification of the agronomic service & 0.2 & - & 0.25 & - & - & - \\
\hline
\end{tabular}

Table 3 Relationship matrix, $W_{i j}$

\begin{tabular}{|c|c|c|c|c|c|c|c|c|c|c|}
\hline Concept & C1 & $\mathrm{C} 2$ & $\mathrm{C} 3$ & C4 & $\mathrm{C} 5$ & C6 & C7 & $\mathrm{C} 8$ & C9 & $\mathrm{C} 10$ \\
\hline $\mathrm{C} 1$ & 0 & 0 & 0 & 0 & 0 & 0 & 0 & 0 & 0 & 0 \\
\hline$C 2$ & 0.2 & 0 & 0 & 0 & 0.4 & 0.4 & 0 & 0 & 0 & 0 \\
\hline $\mathrm{C} 3$ & 0.6 & 0 & 0 & 0 & 0 & 0 & 0 & 0 & 0 & 0 \\
\hline C4 & 0.6 & 0 & 0 & 0 & 0 & 0.4 & 0 & 0 & 0 & 0 \\
\hline $\mathrm{C} 5$ & 0.9 & 0 & -0.1 & 0 & 0 & 0.6 & 0 & 0 & 0 & 0 \\
\hline C6 & -0.8 & 0 & 0 & 0 & 0 & 0 & 0 & 0 & 0 & 0 \\
\hline$C 7$ & 0.8 & 0 & 0.6 & 0 & 0 & 0.6 & 0 & 0 & 0 & 0 \\
\hline $\mathrm{C} 8$ & 0 & 0 & -0.2 & 0 & 0 & -0.8 & 0 & 0 & 0 & 0 \\
\hline C9 & 0 & 0 & 0.8 & 0.2 & 0.4 & -0.6 & 0.8 & 0.8 & 0 & 0 \\
\hline $\mathrm{C} 10$ & 0 & 0 & 0 & 0 & 0 & 0 & 0.8 & 0.8 & 0.9 & 0 \\
\hline
\end{tabular}

factors: additional impact on the qualification of the agronomical service by means of training, addition of new systems for recording the ongoing works, etc. (Scz. 1); increase in the amount of fertilizers, point application according to the soil selection, etc. (Scz. 2); increase in the number of lilacs, point impact on the origins (Scz. 3); partial replacement of the elements of land cultivation technology (Scz. 4).

The matrix representation of the fuzzy cognitive map (the $W_{i j}$ Weight matrix) obtained after expert interviews is shown in Table 3. As we can see, some concepts (C8, C9 and C10) according to experts, do not have a direct impact on the output concept $(\mathrm{C} 1)$.

Graphical representation of the fuzzy cognitive map is shown in Fig. 2. The output concept of $\mathrm{C} 1$ has five positive and one negative impact arcs. All concepts, except $\mathrm{C} 2$ and $\mathrm{C} 10$, have both input and output impact pulses. We believe that this model reflects the simplified structure of the factors influencing the yield to a sufficient extent to obtain an adequate assessment of the modeling results.

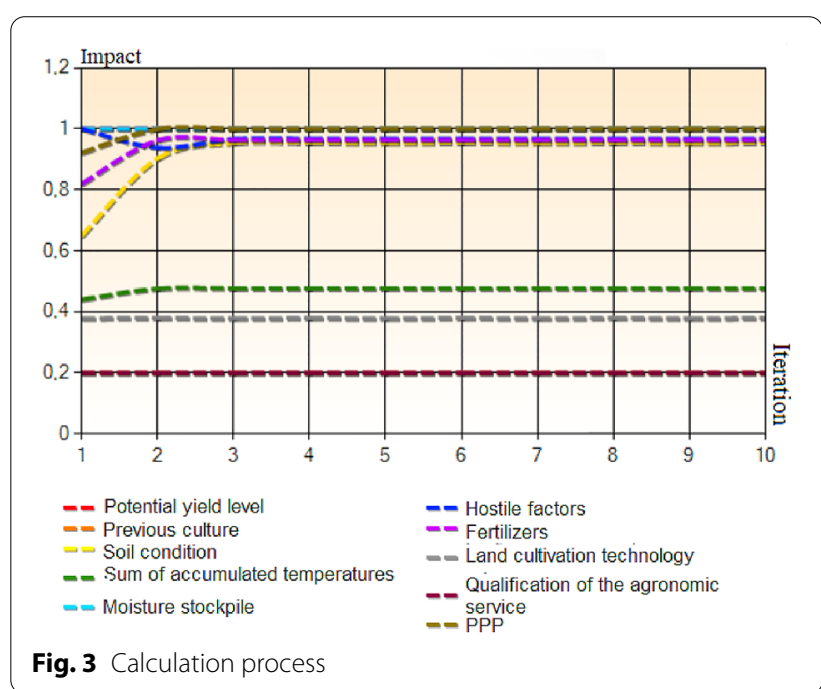


Table 4 Modeling results

\begin{tabular}{lllllllll}
\hline No. & Initial trend & $\begin{array}{l}\text { Desirable dynamics of } \\
\text { the factor }\end{array}$ & Target value & Free development & Scz 3 & Scz 1 & Scz 4 & Scz 2 \\
\hline C1 & 0 & +1 & 1 & 1 & 1 & 1 & 1 \\
C6 & 0.6 & -1 & 0.25 & 0.97 & 0.77 & 0.82 & 0.85 & 1 \\
\hline
\end{tabular}

Table 5 Script rating

\begin{tabular}{lllll}
\hline & Achievement of targets & $\begin{array}{l}\text { Price of impact on the } \\
\text { resource }\end{array}$ & $\begin{array}{l}\text { Time of effect } \\
\text { manifestation }\end{array}$ & $\begin{array}{l}\text { The } \\
\text { final } \\
\text { place }\end{array}$ \\
\hline Skills development (scenario 1) & 2 & 1 & 2 & 2 \\
Fertilizer increase (scenario 2) & 4 & 1 & 1 & 2 \\
Increase in PPPs (scenario 3) & 1 & 1 & 1 & 1 \\
Technology change (scenario 4) & 3 & 3 & 3 & 3 \\
\hline
\end{tabular}

\section{Discussion of results}

In the process of simulation calculations, the concepts were stabilized at the third iteration (Fig. 3). After obtaining the final solution vector for free and controlled development (Table 4), we will compare the results of modeling. The table immediately ranks the scenarios of impact from the best to the worst based on the correspondence of the desired behavior of the system in comparison with the target factors. Scenario 3 is the best, where the controlling influence is the plant protection products that suppress the development of hostile factors. The rest of the scenarios are worse for reducing the negative factors, but still contribute to the growth of yields.

It can be concluded that with free development, when there is no controlling influence, the system does not achieve our goal of reducing hostile factors. Therefore, it is necessary to use control factors that will influence the system already in the process of plant development. Let us compare the simulation results with the amount of economic investments and time costs (Table 5). In this situation, the third scenario wins according to the average assessment of the three factors considered. In second place is the first scenario, which gets the second place only on the basis of rounding off the average score. It may be worth considering a scenario in which the use of plant protection products should be combined with human development.

Consider the influence of factors affecting the level of yield on the consistency of expert opinion (Fig. 4).

To do this, the agronomists first act as experts who make an initial assessment of the concepts, then the input data are fed into a cognitive model, the results of which are then used in the annual summary reporting.

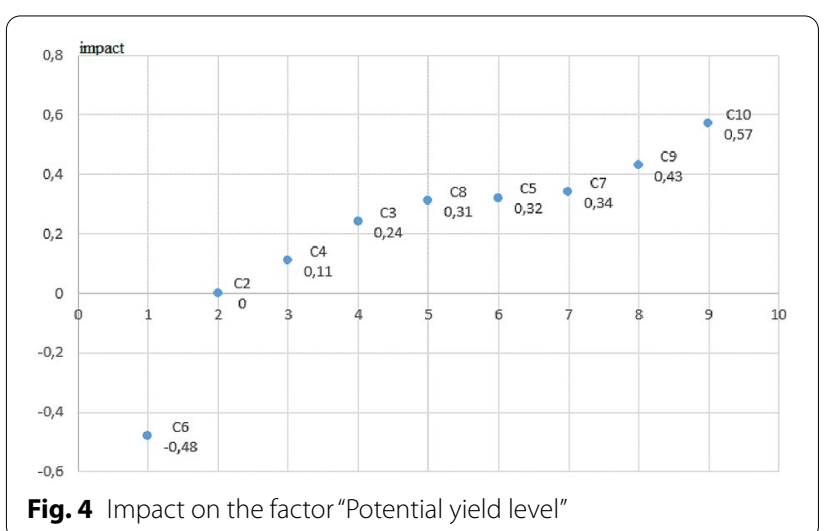

It turns out that agricultural machinery, mechanization, labor organization and fertilizers applied have the greatest positive impact (concepts C10, C9, C7). In other words, these are controllable factors that we can influence with a certain economic price. In addition, there are natural factors (water reserves, soil conditions, etc.) that are more difficult and expensive to influence, but which can be indirectly influenced by cultivation technologies.

In the process of modeling, the fuzzy cognitive map changed its configuration depending on the experts' corrections. It was found that if a negative value was specified in the initial concept state estimation vector, then the results of modeling by the influence of factors would be inverted (so hostile factors contributed to the growth of yield). When constructing the graph, we tried to avoid using loops between the two factors. The current fuzzy cognitive map reacts quite sharply to the change of factors "Technology of land cultivation", "Qualification of the agronomic service", "Water reserve". This is manifested 
in the change in the picture of the impact on the factor "Potential yield level".

\section{Conclusions}

In this research study, the factors influencing the reduction of the potential maximum yield of winter wheat in weather conditions of dry farming in European part of Russia, Volgograd region is considered and analyzed. The method of Fuzzy Cognitive Maps (FCM) is used to address this problem and very interesting results have been obtained.

The obtained conclusions as a result of this research work confirm the concept of precision farming: the quantity and quality of innovations in agriculture depends on the ability to apply effectively them in the field. This method of predicting potential yield levels can be used not only to model future agricultural performance, but also to estimate harvested crops. To do this, the agronomic service can use the FCM toolkit to model and assess factors that influenced yields. This study thoroughly examined the importance of agriculture and farming and their role in daily life. Structural changes in the agricultural sector have created a healthy demand for scientists with deep knowledge of mathematical methods, business and agricultural economics. The benefits to be obtained, from this research study are chiefly due to increased yields and/or increased profitability of production to the farmer. Other benefits come from better working conditions, increased animal welfare and the potential to improve various aspects of environmental stewardship.

Economists based on the results of this research study and acquired skills find employment easier in the private and public sectors; potential employers include banks, financial institutions, advisory services, agricultural cooperatives, supportive and lobbying organizations, and government authorities. Some of our students are also self-employed, either as consultants or in their own agricultural business. Graduate students are also well prepared for conducting their doctoral studies.

A stable agricultural sector ensures food security for the nation. The main requirement of any country is food security. Food security prevents malnutrition and famine, which have traditionally been considered one of the main problems facing developing countries. Most countries rely on agricultural products as well as related industries as their main source of income.

Future resaech would involve to use the Advanced Fuzzy Cognitive Maps (AFCM) which utilizes the state space approach and learning methods to further explore the potential maximum yield of winter wheat in weather conditions of dry farming in various parts of Russia as well on other regions of northen regions of
Europe, [37-39]. Variables to appropriate farming practices such as tillage, seeding, fertilization, herbicide and pesticide application, harvesting and animal husbandry can be considered when the FCM model is developed. Needed software tools for the proposed method should be developed.

\section{Abbreviations}

AFCM: Advanced fuzzy cognitive maps; ANN: Artificial neural network; CDS: complex dynamic systems; DOC: Desired output concept; FCM: Fuzzy cognitive maps; KPI: Key performance indicator; PPP: Plant protection products.

\section{Acknowledgements}

Not applicable.

\section{Authors' contributions}

IS researched the subject area, conducted experiments. MA and MS developed forecasting method. VT made a research of related work. PG developed a forecasting method using FCM. All authors read and approved the final manuscript.

\section{Funding}

Not applicable.

\section{Availability of data and materials}

The data sets used and/or analysed during the current study are available from the corresponding author on reasonable request.

\section{Declarations}

Ethics approval and consent to participate

Not applicable.

\section{Consent for publication}

Not applicable.

\section{Competing interests}

The authors declare that they have no competing interests.

\section{Author details}

${ }^{1}$ Volgograd State Technical University, Volgograd, Russia. ${ }^{2}$ University of Patras, Patras, Greece.

Received: 17 November 2020 Accepted: 8 June 2021

Published online: 28 August 2021

\section{References}

1. Ageev VV, Yesaulko AN, Gorbatko LS, Grechishkina YI, Litvinenko MV, Radchenko VI. Mathematical and regulatory support for crop programming. Stavropol SAU. Stavropol, 2004.

2. Kosko B. Fuzzy cognitive maps. Int J Man-Mach Stud. 1986;24(1):65-75.

3. Kokkinos K, Karayannis V, Moustakas K. Circular bio-economy via energy transition supported by Fuzzy Cognitive Map modeling towards sustainable low-carbon environment. Sci Total Environ. 2020;137754.

4. Tepes A, Neumann MB. Multiple perspectives of resilience: a holistic approach to resilience assessment using cognitive maps in practitioner engagement. Water Res. 2020;115780.

5. Falcone PM, De Rosa SP. Use of fuzzy cognitive maps to develop policy strategies for the optimization of municipal waste management: a case study of the land of fires (Italy). Land Use Policy. 2020;96:104680.

6. Ginis LA. Pulse modeling on fuzzy cognitive maps. Izvestia UFU. Technical Sciences. 2008;10. https://cyberleninka.ru/article/n/impulsnoe-model irovanie-na-nechetkih-kognitivnyh-kartah. Accessed 20 May 2020.

7. Al-Gunaid Mohammed A, Shcherbakov MV, Trubitsin VN, Shumkin AM, Dereguzov KY. Analysis a short-term time series of crop sales based on 
machine learning methods creativity in intelligent technologies and data science (CIT\&DS 2019). In: Third Conference (Volgograd, Russia, September 16-19, 2019) : Proceedings. Part I / Editors: A. Kravets, P. Groumpos, M. Shcherbakov, M. Kultsova ; Volgograd State Technical University [et al.]. Cham (Switzerland) : Springer Nature Switzerland AG, 2019; pp. 189-200. (Ser. Communications in Computer and Information Science (CCIS); Volume 1083).

8. Nosonov AM. Modern methods of modeling agricultural development. Vestnik MGOU. Series: Natural sciences. 2018;3. https://cyberleninka.ru/ article/n/sovremennye-metody-modelirovaniya-razvitiya-selskogo-hozya ystva. Accessed 20 May 2020.

9. Makrinos A, Papageorgiou El, Stylios CD, Gemtos TA. Introducing Fuzzy Cognitive Maps for decision making in precision agriculture. In: Precision Agriculture 2007-Papers Presented at the 6th European Conference on Precision Agriculture, ECPA 2007.

10. Romero JR, Roncallo PF, Akkiraju PC, Ponzoni I, Echenique VC, Carballido JA. Using classification algorithms for predicting durum wheat yield in the province of Buenos Aires. Comput Electron Agricult. 2013;96:173-9.

11. Mkhabela MS, Bullock P, Raj S, Wang S, Yang Y. Crop yield forecasting on the Canadian Prairies using MODIS NDVI data. Agricult For Meteorol. 2011;151(3):385-93.

12. Bolton DK, Friedl MA. Forecasting crop yield using remotely sensed vegetation indices and crop phenology metrics. Agricult For Meteorol. 2013;173:74-84.

13. Natarajan R, Subramanian J, Papageorgiou El. Hybrid learning of fuzzy cognitive maps for sugarcane yield classification. Comput Electron Agricult. 2016;127:147-57.

14. Papageorgiou El, Aggelopoulou KD, Gemtos TA, Nanos GD. Yield prediction in apples using fuzzy cognitive map learning approach. Comput Electron Agricult. 2013;91:19-29.

15. Tagarakis A, Koundouras S, Papageorgiou El, Dikopoulou Z, Fountas S, Gemtos TA. A fuzzy inference system to model grape quality in vineyards. Precision Agricult. 2014;15(5):555-78.

16. Fabbrizzi S, Sacchelli S, Menghini S, Bernetti I. Coping with the economic crisis in agriculture: an analysis of the Tuscany (Italy) premium quality wine area and strategies for impact mitigation. New Medit. 3. 2015.

17. Dai Fuqiang, Zhou Q, Lv Zhiqiang, Wang Xuemei, Liu G. Spatial prediction of soil organic matter content integrating artificial neural network and ordinary kriging in Tibetan Plateau. Ecol Indicat. 2014;45:184-94. https:// doi.org/10.1016/j.ecolind.2014.04.003.

18. Zhu A-X, Qi F, Moore A, Burt JE. Prediction of soil properties using fuzzy membership values. Geoderma. 2010;158(3-4):199-206.

19. Guo Peng-Tao, Li Mao-Fen, Luo Wei, Tang Qun-Feng, Liu Zhi-Wei, Lin Zhao-Mu. Digital mapping of soil organic matter for rubber plantation at regional scale: an application of random forest plus residuals kriging approach. Geoderma. 2015;237-238:49-59. https://doi.org/10.1016/j. geoderma.2014.08.009.

20. Barzman M, Bàrberi P, Birch ANE, Boonekamp P, Dachbrodt-Saaydeh S, Graf B, Sattin M. Eight principles of integrated pest management. Agron Sustain Dev. 2015;35(4):1199-215.

21. Bock $\mathrm{CH}$, Poole GH, Parker PE, Gottwald TR. Plant disease severity estimated visually, by digital photography and image analysis, and by hyperspectral imaging. Crit Rev Plant Sci. 2010;29(2):59-107.

22. Bonfatti BR, Hartemink AE, Giasson E, Tornquist CG, Adhikari K. Digital mapping of soil carbon in a viticultural region of Southern Brazil. Geoderma. 2016;261:204-21.

23. Defraeye T, Verboven P, Ho QT, Nicolai B. Convective heat and mass exchange predictions at leaf surfaces: applications, methods and perspectives. Comput Electron Agricult. 2013;96:180-201.

24. Shcherbakov MV, Brebels A, Shcherbakova NL, Tyukov AP, Yanovskiy TA, Kamaev VA. A survey of forecast error measures. World Appl Sci J (WASJ). 24(24: Information Technologies in Modern Industry, Education \& Society), 2013;171-176.

25. Al-Gunaid Mohammed A. Time series analysis sales of sowing crops based on machine learning methods. In: Mohammed A. Al-Gunaid,
Maxim V. Shcherbakov, Vladislav N. Trubitsin, Alexandr M. Shumkin. Volgograd State Technical University. 2018.

26. Al-Gunaid Mohammed A, Shcherbakov MV, Kamaev VA, Gerget OM, Tyukov AP. Decision trees based fuzzy rules. Information Technologies in Science, Management, Social Sphere and Medicine (ITSMSSM 2016), 2016;51:502-508.

27. Al-Gunaid Mohammed A, Shcherbakov MV, Kravets AG, Loshmanov VI, Shumkin AM, Trubitsin VN, Vakulenko DV. Analysis of drug sales data based on machine learning methods. In: 7th International Conference on System Modeling \& Advancement in Research Trends (SMART-2018, IEEE Conference ID: 44078) (23rd-24th November, 2018) : Proceedings ed. by Rakesh Kumar Dwivedi; College of Computing Sciences \& Information Technology, Teerthanker Mahaveer University (Moradabad, UP, India), IEEE UP Section. New Delhi, 2018;32-38.

28. Jilov RA. On the issue of building cognitive maps for intelligent data processing. Vestnik. KRAUNC. Phys Mat Sci. 2016;(4-1):16. https://cyber leninka.ru/article/n/k-voprosu-o-postroenii-kognitivnyh-kart-dlya-intel lektualnoy-obrabotki-dannyh. Accessed 10 June 2020.

29. Omelchenko AN, Hrustalev OE. Cognitive modeling of the development of the banking system of the Russian Federation in the context of globalization. Finance and Credit. 2011;(41):473. https://cyberleninka.ru/ article/n/kognitivnoe-modelirovanie-razvitiya-bankovskoy-sistemy-rossi yskoy-federatsii-v-usloviyah-globalizatsii. Accessed 10 June 2020.

30. Al-Gunaid MA, Shcherbakov MV, Zadiran KS, Melikov AV. A survey of fuzzy cognitive maps forecasting methods. In: 2017 8th International Conference on Information, Intelligence, Systems \& Applications (IISA) (Larnaca, Cyprus, 27-30 August 2017)/Electrical and Electronic Engineers (IEEE), Biological and Artificial Intelligence Foundation (BAIF), University of Piraeus, University of Cyprus. [Publisher : IEEE], (2017). pp. 1-6. https:// doi.org/10.1109/IISA.2017.8316443[Date Added to IEEE Xplore: 15 March 2018]. Accessed 1 June 2020

31. Al-Gunaid MA. Development of a pulsed fuzzy neural network. In: Mohammed A. Al-Gunaid, M.V. Shcherbakov, editors. Fuzzy systems and soft computing (HCMB-2009): sb. st. 3rd vseros. nauch. konf., 21-24 sep. 2009; VSTU, 2009. T. 2. C. 89-94.

32. Groumpos PP. Intelligence and fuzzy cognitive maps: scientific issues, challenges and opportunities. Stud Inform Control. 2018;27(3):247-64.

33. Groumpos PP. Deep learning vs. wise learning: a critical and challenging overview. Elsevier IFAC-Papers on Line, 2016; pp. 49-29, 180-189. Science Direct.

34. Vokueva TA. The solution of the problem of simulation for cognitive maps of Silov. Inform Technol Manage Econ. 2012;(1):1. https://elibrary.ru/item. asp?id=25910837. Accessed 20 May 2020.

35. Vasilev VI, Savina IA, Sharipova II. Construction of fuzzy cognitive maps for the analysis and management of university information risks. Vestnik UGATU. 2008;2. https://cyberleninka.ru/article/n/postroenie-nechetkihkognitivnyh-kart-dlya-analiza-i-upravleniya-informatsionnymi-riskamivuza. Accessed 1 June 2020.

36. Chekaev NP, Kuznetsov AY. No-till technology - the path to real results. Food Policy Secur. 2015;1. https://cyberleninka.ru/article/n/tehnologiyano-till-put-k-realnym-rezultatam. Accessed 25 May 2020.

37. Mpelogianni VG, Groumpos PP. Re-approaching fuzzy cognitive maps to increase the knowledge of a system. Intern J AI Soc. 2018;1-14.

38. Mpelogianni VG, Groumpos PP (2019) Building energy management system modelling via state fuzzy cognitive maps and learning algorithms. IFAC Papers OnLine 52-25, 2019;513-519.

39. Gurova ON. Dry farming system — the basis for stable and high yields. Sci Agronom J. 2016;1:98. https://cyberleninka.ru/article/n/sistema-suhogozemledeliya-osnova-stabilnyh-i-vysokih-urozhaev. Accessed 15 June 2020.

\section{Publisher's Note}

Springer Nature remains neutral with regard to jurisdictional claims in published maps and institutional affiliations. 